Goldschmidt 2021 Abstract

https://doi.org/10.7185/gold2021.6087

\section{BIF or MIF? Using trace elements to identify the nature of iron formations.}

\author{
VINCENT VAN HINSBERG ${ }^{1}$ AND KRISTOFFER SZILAS ${ }^{2}$ \\ ${ }^{1}$ McGill University \\ ${ }^{2}$ University of Copenhagen \\ Presenting Author: vincent.vanhinsberg@mcgill.ca
}

Banded Iron Formations (BIF) provide key insights into the early Earth. They place constraints on the timing and nature of oxygenation of the oceans and atmosphere, and their elemental compositions hold clues to the concentrations of elements in seawater and the changes therein over time. BIF contain rhythmic layering of Fe-oxides and silicates, interpreted as repetitive changes in sedimentary input potentially modulated by climatic fluctuations. However, layered iron formations can also form by other processes, including metasomatism. These are commonly referred to as pseudo-BIF or Metasomatic Iron Formations (MIF). Whereas classification is unambiguous for major formations, this is not the case for smaller deposits. The latter are important as they reflect time periods not covered by the main episodes of BIF formation.

Here, we present data on the compositions of a diversity of iron formations in the Archaean Tartoq and Isua belts of Greenland. The 3.2 Ga Tartoq supracrustal belt hosts two endmember types: BIF sensu stricto; and magnetite segregations in metasomatised ultramafic rocks (UM-MIF). The latter formed from oxidation and Fe-mobility during metamorphism. UM-MIF can be traced for several kilometres away from the ultramafic bodies, where they transition into rhythmically layered magnetite-silicate gneiss, texturally and mineralogically indistinguishable from the BIF. Similar units are present in Isua.

Magnetite grains in 23 iron formations were analysed by laserablation ICP-QMS for 62 elements, including the REE and PGE. Samples include BIF, UM-MIF, magnetite in meta-basalt, and iron formations of unknown type. REE content and pattern are indistinguishable between BIF and UM-MIF, whereas the magnetite in meta-basalt is strongly REE enriched, with HREE > LREE. UM-MIF has higher $\mathrm{Cr}$ and $\mathrm{Ni}$, and characteristically high $\mathrm{Ni} / \mathrm{Co}$, whereas the BIF has high Ga. All minor IF exposures are similar to the composition of magnetite in basalt, which we interpret as a metamorphic compositional overprint. The only elements not affected by this overprint are the PGEs, with high Ru diagnostic for UM-related deposits.

This study shows that MIF can be indistinguishable from BIF in texture, mineralogy and magnetite composition following metamorphism and fluid-driven element mobilisation. The PGEs, however, remain a robust indicator of their origin.
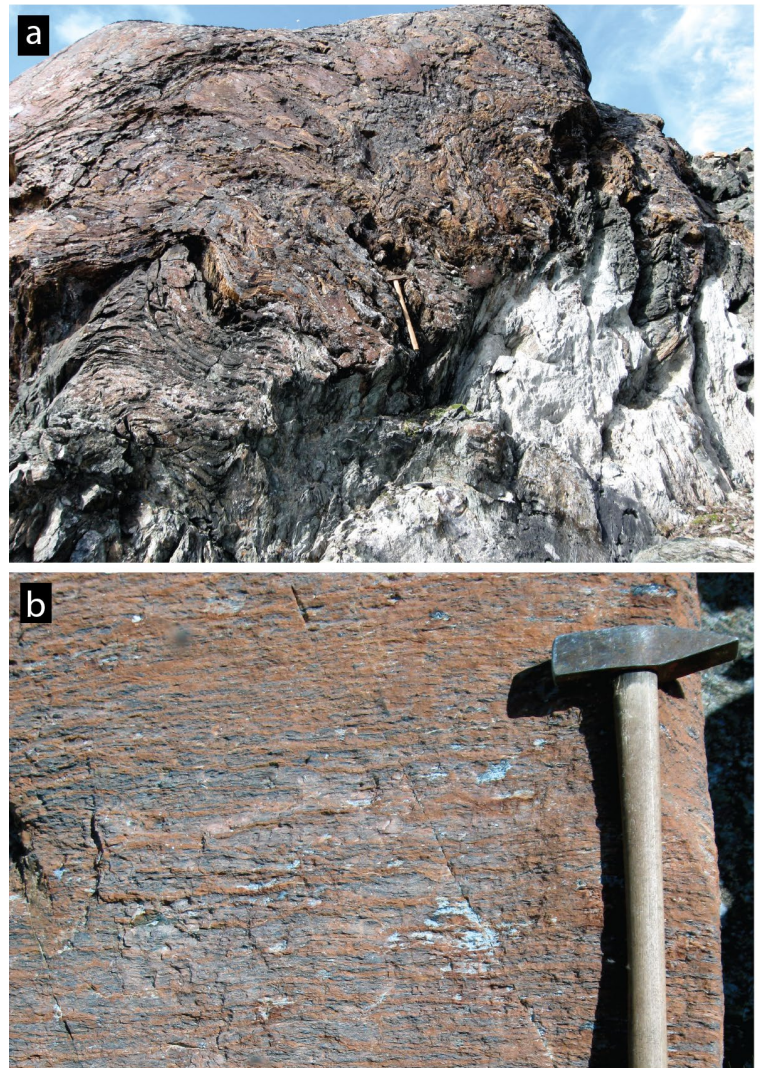

Iron formations in the Tartoq supracrustal belt: a. Folded BIF consisting of alternating layers of magnetite and quartz + grunerite with thrust contact to underlying talc schist; $b$. Magnetite-silicate gneiss (UM-MIF) formed from ultramafic body by metasomatism. 